\title{
Morphology of the Sacral Hiatus in an African Population - Implications for Caudal Epidural Injections
}

Authors: Njihia B.N. ${ }^{1}$ Bsc, Awori K.0. ${ }^{1}$ MBChB, MMed, Dip Orth (SICOT), Gikenye $\mathbf{G}^{1}$ MMed, MBChB. Affiliations: 1 Department of Human Anatomy, University of Nairobi, Nairobi, Kenya. ${ }^{*}$ Correspondence to: B. N. Njihia, Department of Human Anatomy , The University of Nairobi, Riverside Drive off Waiyaki Way, Nairobi, Kenya; Email: benjamin.njihia@gmail.com

\section{Abstract}

\section{Background}

The sacral hiatus exhibits variations in morphology which differ among populations. These variations may influence the success of caudal epidural injections for anaesthesia. This study describes the morphological and morphometric characteristics of the sacral hiatus in an adult Kenyan population.

\section{Study design}

A descriptive cross-sectional study.

\section{Materials and methods}

Eighty eight dry human sacra obtained from the Department of Osteology, National Museums of Kenya, Nairobi were used. The shape of the sacral hiatus was described as inverted-V, dumb-bell, inverted-U or irregular. The distance of the hiatal apex from the lower limit of S2 vertebra, the inter-cornual distance and the apical antero-posterior diameter were measured and tabulated.

\section{Results}

The inverted- $V$ was the most common (32.1\%) shape. The apex of the sacral hiatus was at the level of 4 th sacral vertebra in $62 \%$ of cases. Mean distance of the hiatal apex from the S2 level was $43.1+12.9$ $\mathrm{mm}$ whereas antero-posterior diameter of the sacral hiatus at the apex was $6.4+3.1 \mathrm{~mm}$. The sacral hiatus was absent in $1.2 \%$ of cases.

\section{Conclusion}

The level of the sacral hiatus in the African population implies minimal risk of dural puncture during caudal epidural injections.

\section{Introduction}

The standard description of the sacral hiatus is an arched defect in the posterior wall of the sacral canal formed by the failure in fusion of the laminae of the fifth (and sometimes fourth) sacral vertebra dorsally. The remnants of the inferior articular processes of the fifth sacral vertebra elongate downward on both sides of the hiatus, extending from its apex as the sacral cornua (1). The contents of the sacral canal include the cauda equina, filum terminale and the dural sac that terminates at the level of the second sacral vertebra (1). The sacral hiatus and the cornua are palpable landmarks employed in caudal epidural injections (CEIs) $(2,3)$.

Variations in the morphology of the sacral hiatus based on its shape $(4,5)$ and presence of the hiatus and cornua (6) have been described. These morphological types may influence various morphometric parameters such as the hiatal antero-posterior diameter at the apex, the inter-cornual distance and the distance of the apex from the level of the second sacral vertebra and could influence the success of CEIs (7). Incorrect needle placement has been reported to occur in up to $36 \%$ of cases, even with experienced operators (8).
Data on the pattern of morphological variations and the morphometric parameters of the sacral hiatus in an African population are not available. The aim of this study therefore was to determine the prevalence of morphological variations and establish the morphometric parameters of the sacral hiatus in a Kenyan population.

\section{Materials and Methods}

Eighty eight (88) dry adult human sacra were obtained by systematic random sampling of every 2 nd sacrum from the bone collection of the Osteology department of the National Museums of Kenya, Nairobi. Age was determined by fusion of the sacral epiphyses. Forty (40) sacra were from male subjects, 22 from female and 22 were of indeterminate gender. Measurements were made twice by the first author and the average of the two measures recorded. Inter-observer variability was assessed at the onset of the data collection by scoring observations and measurements of fifteen random sacra by two observers.

The dorsal view of the caudal sacral region was classified morphologically according to Nagar et al. (5). The lower limit of the second sacral vertebral body was determined 


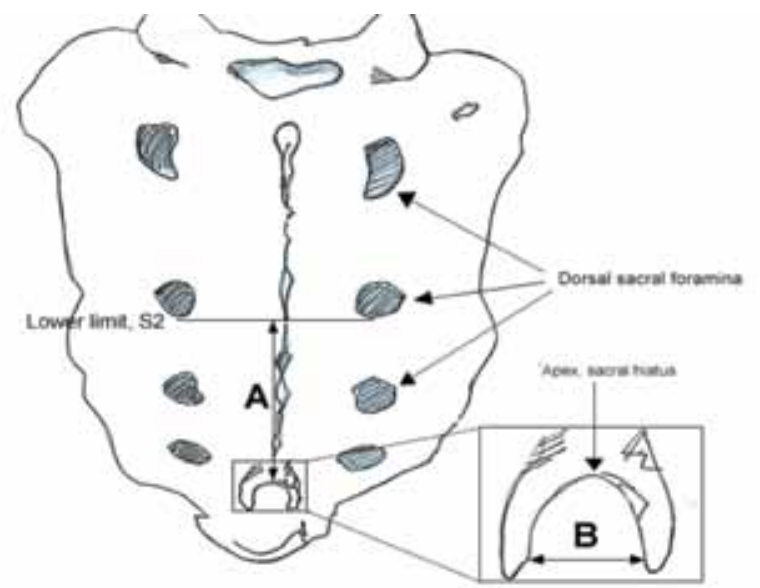

Figure 1: Dorsal view of the human sacrum. A: Distance between the lower limit of the second sacral vertebra and the apex of the sacral hiatus; $B$ : Distance between the cornua at the base of the sacral hiatus

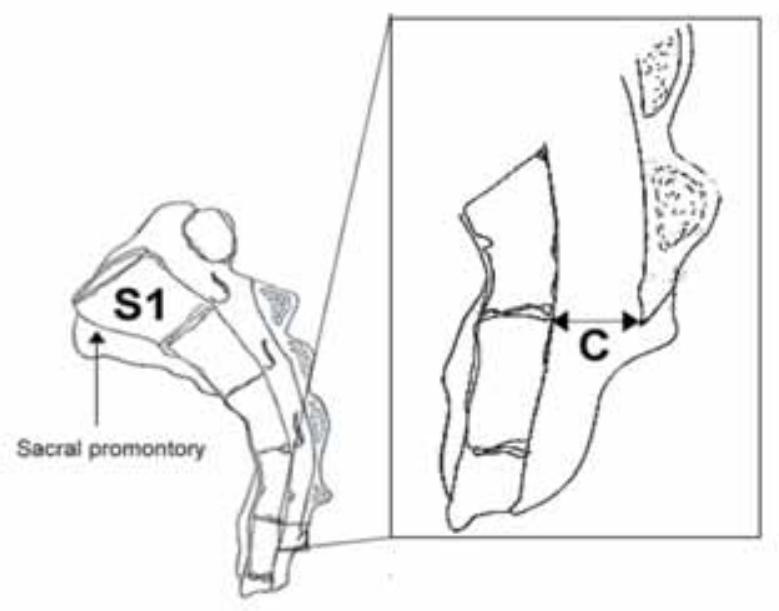

Figure 2: Lateral view of the human sacrum. C: antero-posterior diameter of the sacral hiatus at its apex by an imaginary tangential line between the lower margins of the paired second dorsal sacral foramina (Figure 1). A pair of vernier calipers (SOMET ${ }^{\mathrm{TM}} \mathrm{CN}-25$ 1234; accurate to $1 \mathrm{~mm}$ ) were used to measure the following: (i) distance from the apex of the sacral hiatus to the lower limit of the body of the second sacral vertebra (Figure 1, A), (ii) distance between the cornua (Figure 1, B). The antero-posterior diameter of the sacral hiatus at its apex (Figure 2, C) was measured using a pair of standard geometric dividers and a steel rule (accurate to $1 \mathrm{~mm}$ ). Representative photographs were taken using a digital camera (Kodak ${ }^{\circledR}$ V100).

Observations were made and coded, measurements tabulated and analysis done using SPSS (version 11.5.0 for Windows ${ }^{\mathrm{TM}}$ SPSS Inc., Chicago, Ill.). Frequencies and percentages of the prevalence of morphological types and the level of the apex of the sacral hiatus were calculated. Means, standard deviations and ranges of the morphometric data were then computed.

\section{Results}

Eighty four adult human sacra were analyzed. Four morphological types described by Nagar et al. (5) were ob- served.

The inverted-V shape was the most common (32.1\%) shape. Other shapes included dumbbell (31\%), inverted-U (16.7\%) and irregular (19\%) (Figure 3). The level of the hiatal apex varied between the second and the fifth sacral vertebra. The apex level was the 4 th sacral vertebra in $62.7 \%$ of cases, 3rd and 5th vertebra in $36.2 \%$ respectively. The distance of the apex from the $\mathrm{S} 2$ vertebra was $43.1+12.9 \mathrm{~mm}$ (range 5 to $84 \mathrm{~mm}$ ). Mean inter-cornual distance was $12.6 \mathrm{~mm}$ whereas the mean antero-posterior diameter of the hiatus at its apex was $6.4 \mathrm{~mm}$ (Table 1).

\section{Discussion}

Anatomical variations of the caudal sacrum are thought to influence the outcome of caudal epidural injections (7). Incorrect needle placement during CEIs, even in the hands of experienced operators, has been associated with intra-osseous drug toxicity and aspiration $(8,9,10)$. The current study revealed a prevalence of $32.1 \%$ for the inverted-V morphotype. The results by Nagar et al. (5) recorded a rate of $27 \%$. When the inverted-V and -U morphologies are pooled however, the current results 


\begin{tabular}{|l|l|l|l|}
\hline Morphometric parameter & $\begin{array}{l}\text { Distance of sacral hiatus } \\
\text { apex from the level of } \\
\text { the } 2 \text { nd sacral vertebra }\end{array}$ & $\begin{array}{l}\text { Distance between the } \\
\text { sacral cornua at the } \\
\text { hiatal base }\end{array}$ & $\begin{array}{l}\text { Antero-posterior } \\
\text { diameter of the sacral } \\
\text { hiatus apex }\end{array}$ \\
\hline Mean + SD (mm) & $43.1+12.9$ & $12.6+3.7$ & $6.4+3.1$ \\
\hline Range $(\mathrm{mm})$ & $5-84$ & $5-21$ & $3-18$ \\
\hline
\end{tabular}

Table 1: Morphometric parameters of the sacral hiatus
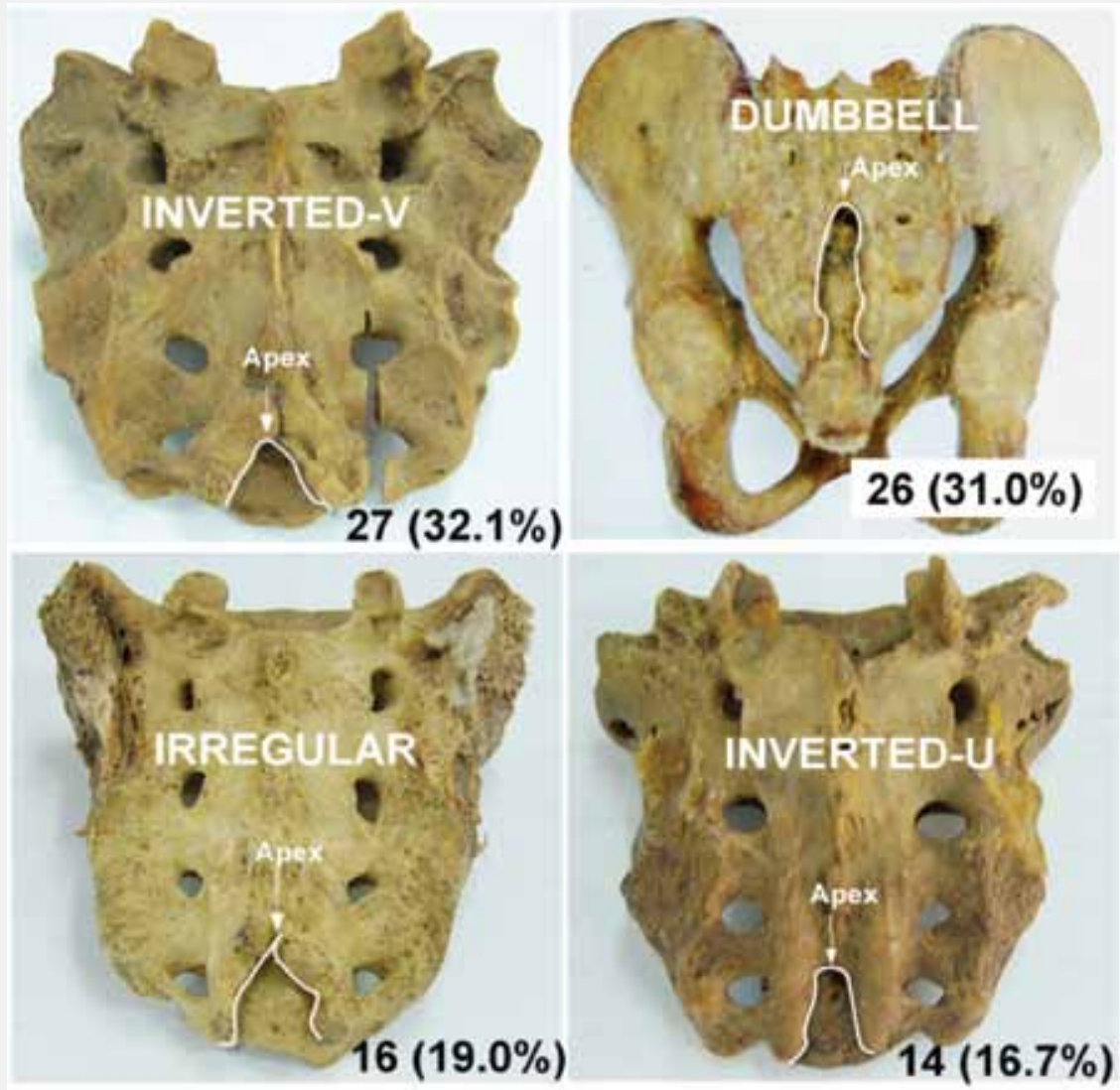

Figure 3: Photomacrographs of most common morphological shapes observed in the current study.

not consider them separately.

In standard texts, the sacral hiatus is described as an arched defect (1). This may be misleading to practitioners who palpate a dumbbell-shaped hiatus (31.0\%, $\mathrm{n}=88$ ) before performing a caudal epidural injection. We posit that the palpation of both the inverted-V and dumbbell morphologies may present two confounders to CEIs. Firstly, the pointed apex of the hiatus in the former presents a smaller 'target' for a needle and may lead to interosseous drug injection, complicating with toxicity. Secondly, palpation of the cornua in the latter morphotype may erroneously guide the operator to inject the drug subcutaneously, outside the sacral canal. This latter scenario could considerably reduce the efficacy of the administered drug.

In the present study the modal vertebral level was S4 (62.7\%). These findings concur with earlier reports $(4,6)$ although the vertebral level of the apex may lie anywhere between S2 and S5 (5).The terminal part of the dural sac usually lies within the sacral spinal canal at the level of the second sacral vertebra (11) and it is therefore safe to suggest that the risk of dural puncture in lower apices is minimal, as the apex was found to lie at the $\mathrm{S} 2$ vertebral level in one case (1.2\%).

The range of the distance of the hiatal apex from the lower limit of the 2 nd sacral vertebra in this study was wide.

(48.8\%) stand apart from earlier reports. Kumar et al. (4) reported a prevalence of $76.3 \%$ for the inverted-V/ inverted-U morphotypes while that by Nagar et al. (5) give a prevalence of $68.5 \%$. We contend that the difference between our study results and earlier ones may be due to an actual difference between the African population and the Indian subjects studied in the two previous works $(4,5)$. The similarity in their pooled results may also suggest that the dichotomy between these two morphological types is not distinct and future studies need
The large range could be related to the morphological types as they present varying hiatal heights (5). Age was eliminated as a possible confounder as only adult sacra were considered in this study. The implications of these morphometric parameters in the process of CEI may include unsatisfactory results in terms of drug penetrance where the distance of the hiatal apex is far from the level of S2. However, the mean distance from the second sacral vertebral level also indicates that chances of dural puncture are minimal. We however still advocate for the 
exercise of caution with due consideration of the lower limit of $5 \mathrm{~mm}$.

In this study, apical diameter had a range of $15 \mathrm{~mm}$ (3$18 \mathrm{~mm}$; mean, $6.4 \mathrm{~mm}$ ). Nagar et al. (5) recorded a mean length of $4.8 \mathrm{~mm}$, ranging from $2-14 \mathrm{~mm}$ whereas Sekiguchi et al. (6) obtained a mean of $6.0+1.9 \mathrm{~mm}$. The inter-cornual distance had a range of $16 \mathrm{~mm}$ (mean, $12.6+3.7 \mathrm{~mm}$ ). This was similar to Sekiguchi et al. (6) where mean was $10.2+0.35 \mathrm{~mm}$ with a range of 2.2 . $18.4 \mathrm{~mm}$.

In conclusion, the inverted-V and dumbbell shapes of the sacral hiatus were the most common in this study and may influence the success of CEIs in the African setting adversely. However, the average antero-posterior diameter of the sacral hiatus at the apex should allow needle access in CEI procedures and practitioners may therefore consider the use of CEIs in the management of LBP and also in anaesthetic procedures. We recommend that further studies evaluate the success of caudal epidural injections in clinical practice in the African setting.

\section{References}

1 Standring S, Ellis H, Healy JC, et al (eds) Williams A. Gray's anatomy-39th edition. Back and Macroscopic Anatomy of Spinal Cord. Elsevier, 2008; 750 - 751

2 Carette S, Leclaire R, Marcoux S, et al. Epidural corticosteroid injections for sciatica due to herniated nucleus pulposus. N Engl J Med. 1997; 336:1634-40

3 Gudaityte J, Marchertiene I, Pavalkis D. Anesthesia for ambulatory anorectal surgery. Medicina (Kaunas), 2004; 40:101-11

4 Kumar V, Pandey SN, Bajpai RN, et al. Morphometrical study of sacral hiatus. J Anat Soc India, 1992; 41:7-13

5 Nagar SK. A study of sacral hiatus in dry human sacra. J Anat Soc India, 2004; 53:18-21

6 Sekiguchi M, Yabuki S, Satoh K, et al. An anatomic study of the sacral hiatus: A basis for successful caudal epidural block. Clin J Pain, 2004; 20:51-54

7 Senoglu N, Senoglu M, Oksuz H, et al. Landmarks of the sacral hiatus for caudal epidural block: an anatomical study. Br J Anaesth, 2005; 95: 692-5

8 Price CM, Rogers PD, Prosser AS, et al. Comparison of the caudal and lumbar approaches to the epidural space. Ann Rheum Dis, 2000; 59: 879-82

9 Ogoke BA. Caudal epidural steroid injections. Pain Physician, 2000 Jul; 3:305-12

10 Manchikanti L, Cash KA, Pampati V, et al. Evaluation of fluoroscopically guided caudal epidural injections. Pain Physician, 2004; 7:81-92

11. Willis RJ. Caudal epidural blockade. In Cousins MJ. ed. Neural Blockade in Clinical Anaesthesia and Management of Pain. 3rd ed. Philadelphia: Lippincott Raven Publishers, $1998 ; 323-342$ 